Research Article

\title{
Coordination of an Environmentally Responsible Supply Chain with Cost Disturbance under Carbon Price Fluctuations
}

\author{
Shijuan $\mathrm{Wu} \mathbb{D}^{1}$ and Zhigang Huang ${ }^{1,2}$ \\ ${ }^{1}$ School of Economics and Management, Fuzhou University, Fuzhou 350108, China \\ ${ }^{2}$ Fujian Key Laboratory of Finance Technology Innovation, Fuzhou 350108, China \\ Correspondence should be addressed to Shijuan Wu; m170710022@fzu.edu.cn
}

Received 12 March 2020; Revised 23 April 2020; Accepted 29 April 2020; Published 11 June 2020

Academic Editor: Neale R. Smith

Copyright @ 2020 Shijuan Wu and Zhigang Huang. This is an open access article distributed under the Creative Commons Attribution License, which permits unrestricted use, distribution, and reproduction in any medium, provided the original work is properly cited.

This paper studies a two-echelon supply chain consisting of a retailer and a manufacturer under carbon emission reduction target and carbon cap-and-trade policy. The unit production cost varies when carbon price fluctuates. We find that carbon price fluctuations affect the original optimal production decision in the supply chain. We also compare how this disturbance affects the supply chain operations under three different power structures with a focus on the profitability and robustness.

\section{Introduction}

Following the concept of sustainable development, lowcarbon economy requires all sectors of society to assume their environmental responsibility. Governments control and coordinate carbon footprints through market mechanisms and strongly support firms to invest in carbon emission reduction. Furthermore, whether the product is environmentally friendly is one of the factors taken into consideration in consumers' decision of purchase. All these environmentally responsible factors will directly affect the firms of manufacturers and retailers. So much attention has been drawn to how supply chains composed of manufacturers and retailers undertake the environmental responsibility and how the environmental responsibility affects their operations and profitability.

In fact, environmental responsibility as part of the corporate social responsibility has historically been a significant theme in academic research $[1,2]$. The environmental responsibility of firms is reducing their carbon footprints below the carbon caps. Commonly they use methods including carbon emission reduction investment or carbon cap-and-trade. The United Nations Climate Change Conference COP 25 (2-13 December 2019) failed to reach a consensus on the implementation details of the marketbased carbon cap-and-trade policy due to the different preferences between countries. The lack of implementation details has brought challenges to the subsequent development of the carbon trading market. Although governments have not reached an agreement on carbon trading matters, the firms have already begun to take actions on carbon emission reduction. Many well-known firms in the world have publicly announced their carbon emission reduction investment goals on their official websites. For example, automotive technology supplier Bosch has publicly disclosed that it will purchase a large amount of green power and increase its investment in renewable power to realize the carbon neutrality in the year of 2020. The household product retailer IKEA stated that it would be carbon neutral by 2030 and the e-business platform Amazon certified that half of its transportation would achieve zero carbon footprints by 2030. Even Shell, the oil firm that faces big difficulty in reducing carbon footprints, has promised to reduce $50 \%$ of its carbon footprints by 2050 .

For firms, both carbon emission reduction investment and carbon cap-and-trade will directly affect their costs. Whether to invest in carbon emission reduction or not and the level of the investment are both controllable factors for firms in their production decisions. However, carbon trading is affected by market factors. Whether the carbon trading markets are efficient or not, there must be fluctuations in carbon prices, which is the uncontrollable factor for 
firms that need extra carbon emission rights. Carbon price fluctuations will cause cost disturbance in the production process, which will cause cost deviation and change the original optimal production decision. Therefore, this paper will focus on how carbon price fluctuations affect the operations and profitability of supply chains.

Furthermore, the power structures of the supply chain in the real economy are not the same, and the supply chains under different power structures have different reactions to cope with cost disturbance caused by carbon price fluctuations. In this paper, we take a two-echelon supply chain including a manufacturer and a retailer as examples. For the manufacturer and the retailer, their different market scales become the bargaining weight of leadership in their supply chain. Generally, this type of two-echelon supply chain has the following three different power structures: a centralized supply chain, a retailer-leading supply chain where downstream retailers have stronger bargaining power, and a manufacturerleading supply chain where upstream manufacturers have stronger bargaining power. A similar setting that consists of a manufacturer and a retailer has been adopted by Wang et al. [3], Zhang et al. [4], and Zheng et al. [5]. Under different power structures, the changes of supply chain operations, profitability, and robustness are worthy of attention.

In summary, this paper focuses on a two-echelon supply chain with one manufacturer and one retailer under the cost disturbance caused by carbon price fluctuations. We compare the supply chain operations, profitability, and robustness under three different power structures in response to cost disturbance caused by carbon price fluctuations.

This paper is structured as follows: Following the introduction is literature review. Section 3 presents the assumptions and notation of the models. Section 4 presents the baseline models without cost disturbance and Section 5 presents the cost disturbance models under carbon price fluctuations. In order to illustrate the models in Sections 4 and 5, we conduct numerical examples in Section 6. Section 7 presents the conclusion.

\section{Literature Review}

2.1. Supply Chain Management under Carbon Cap-and-Trade Policy. Supply chain management under carbon cap-andtrade policy has gained much attention since the last decade. The implementation of cap-and-trade policy is crucial for supply chains to make operation decisions [6]. Existing research tends to be fragmented on carbon trade in the supply chain management. Both Martí et al. [7] and Zakeri et al. [8] focus on the difference between carbon cap-andtrade policy and carbon tax policy, which will affect the operations of supply chains [9]. The carbon cap-and-trade policy is often related to environmental protection and green concepts; for example, Jiang and Chen [10] proposed a supply chain model with both green technology investment and cap-and-trade policy; Chen and Wang [11] examined how carbon trade influences green product mix decision. Wang et al. $[12,13]$ considered the effect of carbon trade on the operations of fresh food supply chains. Jiang et al. [10] and Yuan et al. [14] set up a supply chain system with carbon trade to examine the problem of carbon information asymmetry. Cheng et al. [6] and Xu et al. [15] did research on the impacts of carbon cap-and-trade policy on supply chain systems under the centralized and decentralized operation modes. Pang et al. [16] and Wang et al. [17] introduced consumer environmental awareness into the study of supply chains with carbon trade. There are also some researches on carbon trade referring to make-to-order supply chain $[18,19]$, multiperiod supply chain [20], take-back regulations [21], supply chain with yield uncertainty [22], and supply chain with side-payment contract [23].

2.2. Supply Chain Management with Disturbance. The issue of supply chain disturbance management has received much attention recently. In terms of demand disturbance, the research usually focuses on the direct demand disturbance, market share disturbance, and retail price sensitive disturbance. Among them, direct demand disturbance, that is, sudden increase or decrease in market demand, has received the biggest attention in recent years. Chen et al. [24] paid attention to the influence of direct demand disturbance in a complex supply chain system under the competitive environment. Shen and $\mathrm{Li}$ [25] used direct demand disturbance and supply disturbance as the composition of market disturbance to study the possible risks of supply chains under disturbance. Huang and Wang [26] studied the influence of direct demand disturbance in the closed-loop supply chain. Rahmani and Yavari [27] focused on the impact of direct demand disturbance on the green product supply chain and calculated the value of knowing the demand disturbance in advance. Unlike the aforesaid research, Wang et al. [28] and Ali et al. [29] studied demand disturbance due to changes in market size. The mode of demand disturbance in Zheng et al. [30] research is caused by changes of market size and consumers' retail prices sensitivity. Compared with direct demand disturbance, which treats demand disturbance as a black box, the latter two types of demand disturbances are more reasonable. In particular, market demand disturbance caused by the consumers' retail prices sensitivity can reflect consumers' purchasing psychology and is more in line with the real economy.

In terms of cost disturbance, most of the existing researches focused on the direct production cost disturbance. Sardar and Lee [31] studied the impacts of the direct production cost disturbance on the supply chain in the fast fashion garment. Some scholars focused on the cost disturbance in the closed-loop supply chain. For example, Han et al. [32] examined the robustness when the cost disturbance occurred in closed-loop supply chain; Huang and Wang [33] considered a closed-loop supply chain with online and offline channel under the cost disturbance; $\mathrm{Wu}$ et al. [34] set up a retailer competition environmental closedloop supply chain with cost disturbance. Many researches on cost disturbance also consider demand disturbance at the same time. For instance, Zhang et al. [35] focused on the dual-channel (direct sales and retail sales) sales supply chain under dual disturbance; Zhang et al. [36] studied supply chain operations when suppliers bear cost disturbance and retailers bear demand disturbance; Cao et al. [37] set up a 
retailers' competition environment to examine how the supply chain reacts to the dual disturbance. Soleimani et al. [38] studied the differences of pricing strategy under cost and demand disturbance between centralized and decentralized operation supply chains. Tang et al. [39] compared different operations of supply chains with and without revenue sharing contracts. The above literature on supply chain disturbance management mainly focuses on direct production cost disturbance and assumes that carbon price is fixed in carbon trade market. However, the impact of carbon trade and cost disturbance on supply chains in the real economy will be much more complicated. Thus, it is very meaningful to focus on these kinds of supply chains.

The contributions of this research are twofold:

(1) By introducing carbon cap-and-trade policy into a two-echelon supply chain, we can study the case when the carbon price fluctuates. This paper assumes that the carbon trade market is not completely efficient and there exists speculation in the market, leading to differences between actual and equilibrium carbon prices. We focus on the impact of carbon price fluctuations on the operations of the supply chain. Fluctuated carbon prices furnish an alternative approach to accommodating cost disturbance in the supply chain on top of the traditional direct production cost disturbance.

(2) We consider three cases for the two-echelon supply chain. In the centralized case, a central planner makes operational decisions to maximize the channel profit. In the two decentralized cases, there are two Stackelberg game sets where the manufacturer and the retailer are, respectively, assumed to be the leader in the supply chain. Though previous researches have also taken the different supply chain power structures into consideration, enterprises' environmental responsibility, consumers' environmental awareness, and carbon price fluctuations have not been considered together at the same time. Base on the consideration of enterprises' environmental responsibility and consumers' environmental awareness, this paper examines how different power structures affect the supply chain operations under cost disturbance due to carbon price fluctuations.

\section{Model Assumptions and Notation}

We focus on a two-echelon supply chain with one manufacturer and one retailer. Among them, the manufacturer makes carbon emission reduction investment and the cost disturbance caused by carbon price fluctuations will be directly reflected in the profit of the manufacturer. To study the changes of the supply chain operations under cost disturbance caused by carbon price fluctuations, we employ the notations in Table 1 and the following assumptions.

Assumption 1. Consumer's valuation of the product is $v \sim[0, V]$ and consumer density is 1 (i.e., one consumer per unit length).
Consumers are defined as green consumers. It means that the factors affecting consumer demand include the retail price and the carbon emission reduction investment level. That is, manufacturer investing more in carbon emission reduction and reducing more pollution will increase consumer utility. Therefore, consumer utility can be expressed as $U=v-p+e r$. It can be seen that consumers will buy the product only when the pricing range of the product is $[p-e r, V](p-e r \geq 0)$.

According to the above conditions, the market demand function of the production can be obtained as follows:

$$
q=\int_{p-e r}^{V} 1 \mathrm{~d} v=e r+V-p .
$$

Ensure that demand and profit are positive; then, $V>e t+c$.

Assumption 2. To reduce carbon footprints, the manufacturer will make carbon emission reduction investment. $r$ is used as an indicator of carbon emission reduction investment level and manufacturer can decide it. The cost of the carbon emission reduction investment can be expressed as $\alpha r^{2} / 2$, where $\alpha$ is the efficiency coefficient of carbon emission reduction investment. Due to technology and cost constraints, the manufacturer cannot increase carbon emission reduction investment level indefinitely. It means that $e^{2}<2 \alpha$. Similar assumption has been adopted by Ji et al. [40].

We consider three different power structures of supply chains: centralized supply chain, retailer-leading decentralized supply chain, and manufacturer-leading decentralized supply chain. In the centralized supply chain, the retailer and manufacturer can be considered as a whole, so the decision variables of the supply chain system are $p$ (the product retail price) and $r$ (the carbon emission reduction investment level). In the retailer-leading decentralized supply chain, because the retailer has stronger bargaining power, the retailer will first determine its own profit margin $(m)$; the manufacturers can only determine the product wholesale price $(w)$ and carbon emission reduction investment level $(r)$ according to the retailer's decision. In the manufacturer-leading supply chain, because the manufacturer has stronger bargaining power, it will first determine the product wholesale price $(w)$ and its carbon emission reduction investment level $(r)$, and the retailer will determine the product retail price $(p)$ according to the manufacturer's decision to obtain its optimal profit margin $(m)$. Figure 1 shows the structure of the supply chain.

\section{Baseline Models without Carbon Price Fluctuations}

Assuming that the carbon trading market is completely efficient, all market information has been fully reflected in the price of carbon emission rights. At this time, the carbon price is in equilibrium and there is no fluctuation and no speculation. We set up baseline models without carbon price fluctuations under three different power structures: (i) centralized, (ii) retailer-leading decentralized, and 
TAble 1: Parameter notations.

\begin{tabular}{|c|c|}
\hline \multicolumn{2}{|r|}{ Given parameters } \\
\hline$c$ & Unit cost of a product, $c>0$ \\
\hline$p$ & Retail price, $p=w+m>0$ \\
\hline$w$ & Manufacturer wholesale price, $w>0$ \\
\hline$m$ & Retailer marginal profit, $m>0$ \\
\hline$q$ & Production quantity, $q>0$ \\
\hline$v$ & Consumer valuation of the product, $v>0$ \\
\hline$e$ & Sensitivity coefficient of carbon emission reduction level (consumers' environmental awareness), $e>0$ \\
\hline$r$ & $\begin{array}{c}\text { Carbon emission reduction investment level, } 0<r<q-R \text { (assume that the carbon emission per unit product is } 1 \text { and consider the } \\
\text { manufacturer as the demand side of carbon emission rights) }\end{array}$ \\
\hline$R$ & Carbon emission cap, $R>0$ \\
\hline$t$ & Carbon price, $t>0$ \\
\hline$o$ & Carbon price fluctuation \\
\hline$\mu_{1}$ & Shortage cost \\
\hline$\mu_{2}$ & Inventory cost \\
\hline$U$ & Consumer's utility function \\
\hline$d$ & Demand function \\
\hline$\pi$ & Profit function \\
\hline \multicolumn{2}{|r|}{ Superscripts/subscripts } \\
\hline()$^{*}$ & Optimal result without carbon price fluctuations \\
\hline$(\tilde{)}$ & Optimal result with carbon price fluctuations \\
\hline()$_{c}$ & The result of centralized supply chain \\
\hline()$_{r}$ & The result of retailer-leading decentralized supply chain \\
\hline()$_{m}$ & The result of manufacturer-leading decentralized supply chain \\
\hline$\pi^{r}$ & The profit of retailer in the decentralized supply chain \\
\hline$\pi^{m}$ & The profit of manufacturer in the decentralized supply chain \\
\hline
\end{tabular}

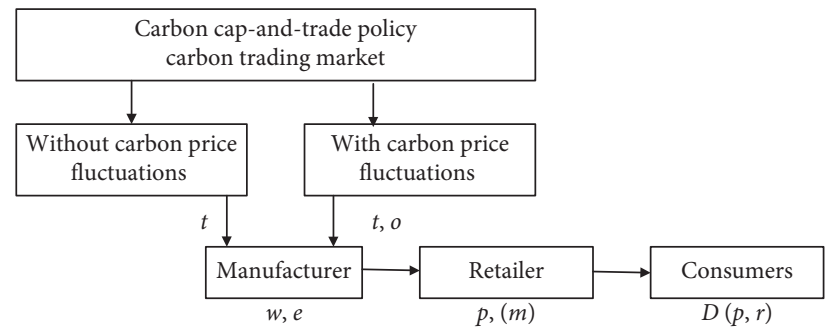

FIgURE 1: Supply chain structure with and without carbon price fluctuations.

(iii) manufacturer-leading decentralized. They serve as the reference to understand the impact of carbon price fluctuations on the operations of the supply chain.

4.1. Baseline Model: Centralized Supply Chain. In the centralized supply chain, the retailer and the manufacturer make decisions concertedly, so the target profit function at this time can be expressed as

$$
\pi_{c}^{*}\left(p_{c}^{*}, r_{c}^{*}\right)=\left(p_{c}^{*}-c\right) q_{c}^{*}-\left(q_{c}^{*}-r_{c}^{*}-R\right) t-\frac{\alpha r_{c}^{* 2}}{2} \text {. }
$$

In the previous equation, $\left(q_{c}^{*}-r_{c}^{*}-R\right) t$ represents the impact of carbon cap-and-trade policy on the profit of the supply chain. Since the manufacturer in this paper is assumed as the demander of carbon emission rights and its initial carbon cap cannot meet its production requirement, the manufacturer must purchase carbon emission rights from the carbon trading market. It means that $\left(q_{c}^{*}-r_{c}^{*}-R\right) t>0$. The optimization theory can be used to obtain the optimal production decision of this model.

Proposition 1. The optimal production decision of this model is

$$
\begin{aligned}
& p_{c}^{*}=\frac{e[c e+(e-1) t]-(c+t+V) \alpha}{e^{2}-2 \alpha}, \\
& r_{c}^{*}=\frac{-2 t+e(c+t-V)}{e^{2}-2 \alpha} .
\end{aligned}
$$

At this time, the optimal production quantity is consistent with market demand.

$$
q_{c}^{*}=\frac{-e t+(c+t-V) \alpha}{e^{2}-2 \alpha} .
$$

Proof. According to formula (2), the Hessian matrix of $\pi_{c}^{*}$ about $\left(p_{c}^{*}, r_{c}^{*}\right)$ is

$$
\mathrm{HM}_{c}=\left[\begin{array}{cc}
-2 & e \\
e & -\alpha
\end{array}\right]
$$

Because of $e^{2}<2 \alpha$, the Hessian matrix $\left|\mathrm{HM}_{c}\right|=2 \alpha-e^{2}>0$; thus $\pi_{c}^{*}\left(p_{c}^{*}, r_{c}^{*}\right)$ has the optimal solution. By solving $\partial \pi_{c}^{*}\left(p_{c}^{*}, r_{c}^{*}\right) / \partial p_{c}^{*}=0$ and $\partial \pi_{c}^{*}\left(p_{c}^{*}, r_{c}^{*}\right) / \partial r_{c}^{*}=0$ simultaneously, we can obtain $p_{c}^{*}$ and $r_{c}^{*}$. This concludes the proof of Proposition 1 . 
At this time, the optimal production quantity is consistent with market demand; put known $p_{c}^{*}$ and $r_{c}^{*}$ into the equation $q_{c}^{*}=-p_{c}^{*}+e r_{c}^{*}+V$ and get the result $q_{c}^{*}=[-e t+(c+t-V) \alpha] /\left(e^{2}-2 \alpha\right)$. Similarly, according to known $p_{c}^{*}, r_{c}^{*}$, we can get the profit of centralized supply chain $\pi_{c}^{*}\left(p_{c}^{*}, r_{c}^{*}\right)$.

4.2. Baseline Model: Retailer-Leading Decentralized Supply Chain. In the retailer-leading decentralized supply chain, the retailer will first determine its own marginal profit $(m)$ to maximize its own profit, and then the manufacturer will determine the wholesale price $(w)$ and carbon emission reduction investment level $(r)$ according to retailer's decision. Thus, we can get the profit of the retailer and manufacturer as follows:

$$
\begin{gathered}
\pi_{r}^{r *}\left(w_{r}^{*}, m_{r}^{*}, r_{r}^{*}\right)=m_{r}^{*} q_{r}^{*}, \\
\pi_{r}^{m *}\left(w_{r}^{*}, m_{r}^{*}, r_{r}^{*}\right)=\left(w_{r}^{*}-c\right) q_{r}^{*}-\left(q_{r}^{*}-r_{r}^{*}-R\right) t-\frac{\alpha r_{r}^{* 2}}{2},
\end{gathered}
$$

Using optimization theory, we can get the optimal decisions of the retailer-leading decentralized supply chain.

Proposition 2. The optimal production decision of the retailer-leading supply chain is

$$
\begin{aligned}
& w_{r}^{*}=\frac{e[-t+2 e(c+t)-3(c+t)+V] \alpha}{2\left(e^{2}-2 \alpha\right)}, \\
& m_{r}^{*}=\frac{e t-(c+t-V) \alpha}{2 \alpha}, \\
& r_{r}^{*}=\frac{e^{2} t-4 t \alpha+e(c+t+V) \alpha}{2\left(e^{2}-2 \alpha\right) \alpha} .
\end{aligned}
$$

At this time, the production quantity under the optimal decision of this supply chain is

$$
q_{r}^{*}=\frac{-e t+(c+t+V) \alpha}{2\left(e^{2}-2 \alpha\right)} .
$$

Proof. According to formula (7), the Hessian matrix of $\pi_{r}^{m *}$ about $\left(w_{r}^{*}, m_{r}^{*}, r_{r}^{*}\right)$ is

$$
\mathrm{HM}_{r}=\left[\begin{array}{cc}
-2 & e \\
e & -\alpha
\end{array}\right] .
$$

The Hessian matrix $\left|\mathrm{HM}_{r}\right|=2 \alpha-e^{2}>0$; thus $\pi_{r}^{m *}\left(w_{r}^{*}, m_{r}^{*}, r_{r}^{*}\right)$ has optimal solution. By solving

$$
\begin{aligned}
& \frac{\partial \pi_{r}^{m *}\left(w_{r}^{*}, m_{r}^{*}, r_{r}^{*}\right)}{\partial w_{r}^{*}}=0, \\
& \frac{\partial \pi_{r}^{m *}\left(w_{r}^{*}, m_{r}^{*}, r_{r}^{*}\right)}{\partial r_{r}^{*}}=0,
\end{aligned}
$$

simultaneously, we can get

$$
\begin{aligned}
w_{r}^{*}\left(m_{r}^{*}\right) & =\frac{e[c e+(e-1) t]-\left(c-m_{r}^{*}+t+V\right) \alpha}{e^{2}-2 \alpha}, \\
r_{r}^{*}\left(m_{r}^{*}\right) & =\frac{-2 t+e\left(c+m_{r}^{*}+t-V\right)}{e^{2}-2 \alpha} .
\end{aligned}
$$
get

Putting $w_{r}^{*}\left(m_{r}^{*}\right)$ and $r_{r}^{*}\left(m_{r}^{*}\right)$ into formula (6), we can

$$
\pi_{r}^{r *}\left(m_{r}^{*}\right)=\frac{m[-e t+(c+m+t-V) \alpha]}{e^{2}-2 \alpha} .
$$

The second derivative of $\pi_{r}^{r *}\left(m_{r}^{*}\right)$ about $m_{r}^{*}$ is

$$
\frac{d^{2} \pi_{r}^{r *}\left(m_{r}^{*}\right)}{\mathrm{d} m_{r}^{* 2}}=\frac{2 \alpha}{e^{2}-2 \alpha} .
$$

Knowing that $\alpha>0$ and $e^{2}-2 \alpha<0$, we have $\left(\mathrm{d}^{2} \pi_{r}^{r *}\left(m_{r}^{*}\right) / \mathrm{d} m_{r}^{* 2}\right)<0 . \quad \pi_{r}^{r *}\left(m_{r}^{*}\right)$ is a strictly concave function of $m_{r}^{*}$, so $\pi_{r}^{r *}\left(m_{r}^{*}\right)$ has optimal solution. The optimal solution is $m_{r}^{*}$ when $\mathrm{d} \pi_{r}^{r *}\left(m_{r}^{*}\right) / \mathrm{d} m_{r}^{*}=0$. Putting the obtained $m_{r}^{*}$ into $w_{r}^{*}\left(m_{r}^{*}\right)$ and $r_{r}^{*}\left(m_{r}^{*}\right)$, we can get $w_{r}^{*}$ and $r_{r}^{*}$. This concludes the proof of Proposition 2.

According to known $w_{r}^{*}, m_{r}^{*}, r_{r}^{*}$, we can get the optimal quantity $\left(q_{r}^{*}\right)$ and profit $\pi_{r}^{r *}\left(w_{r}^{*}, m_{r}^{*}, r_{r}^{*}\right)$ and $\pi_{r}^{m *}\left(w_{r}^{*}, m_{r}^{*}, r_{r}^{*}\right)$ of the retailer-leading supply chain.

4.3. Baseline Model: Manufacturer-Leading Decentralized Supply Chain. In the manufacturer-leading decentralized supply chain, the manufacturer will first determine the product wholesale price $(w)$ and the carbon emission reduction investment level $(r)$ to maximize its own profit, and then the retailer will determine its marginal profit $(m)$ according to manufacturer's decision; thus, the profits of retailer and manufacturer are

$$
\pi_{m}^{r *}\left(p_{m}^{*}, w_{m}^{*}, r_{m}^{*}\right)=\left(p_{m}^{*}-w_{m}^{*}\right) q_{m}^{*}
$$

$$
\pi_{m}^{m *}\left(p_{m}^{*}, w_{m}^{*}, r_{m}^{*}\right)=\left(w_{m}^{*}-c\right) q_{m}^{*}-\left(q_{m}^{*}-r_{m}^{*}-R\right) t-\frac{\alpha r_{m}^{* 2}}{2}
$$

According to the optimization theory, we can get the optimal decisions of the manufacturer-leading decentralized supply chain.

Proposition 3. The optimal production decision of the manufacturer-leading supply chain is

$$
\begin{aligned}
& w_{m}^{*}=\frac{e[c e+(-2+e) t]-2(c+t+V) \alpha}{e^{2}-4 \alpha}, \\
& m_{m}^{*}=\frac{-e t+(c+t+V) \alpha}{e^{2}-4 \alpha}, \\
& r_{m}^{*}=\frac{-4 t+e(c+t+V)}{e^{2}-4 \alpha} .
\end{aligned}
$$


At this time, the production quantity under the optimal decision of this supply chain is

$$
q_{m}^{*}=\frac{-e t+(c+t+V) \alpha}{e^{2}-4 \alpha} .
$$

Proof. According to formula (15), we can get

$$
\frac{\mathrm{d}^{2} \pi_{m}^{r *}\left(p_{m}^{*}, w_{m}^{*}, r_{m}^{*}\right)}{\mathrm{d} p_{m}^{* 2}}=-2<0
$$

So $\pi_{m}^{r *}\left(p_{m}^{*}, w_{m}^{*}, r_{m}^{*}\right)$ is a strictly concave function of $p_{m}^{*}$ and $\pi_{m}^{r *}\left(p_{m}^{*}, w_{m}^{*}, r_{m}^{*}\right)$ has optimal solution. That solution is $p_{m}^{*}$ when

$$
\frac{\mathrm{d} \pi_{m}^{r *}\left(p_{m}^{*}, w_{m}^{*}, r_{m}^{*}\right)}{\mathrm{d} p_{m}^{*}}=0 .
$$

By calculation, we can get $p_{m}^{*}\left(w_{m}^{*}, r_{m}^{*}\right)=(1 / 2)\left(e r_{m}^{*}+\right.$ $\left.V+w_{m}^{*}\right)$ and putting it to formula (16) we can get

$$
\begin{aligned}
\pi_{m}^{m *}\left(w_{m}^{*}, r_{m}^{*}\right)= & \frac{1}{2}\left[2 R t-t V-c\left(e r_{m}^{*}+V-w_{m}^{*}\right)+t w_{m}^{*}\right. \\
& \left.+V w_{m}^{*}-w_{m}^{* 2}+r_{m}^{*}\left(2 t-e t+e w_{m}^{*}\right)-r_{m}^{* 2} \alpha\right] .
\end{aligned}
$$

So the Hessian matrix of $\left(w_{m}^{*}, r_{m}^{*}\right)$ is

$$
\mathrm{HM}_{m}=\left[\begin{array}{cc}
-1 & e / 2 \\
e / 2 & -\alpha
\end{array}\right] \text {. }
$$

Because of $e^{2}<2 \alpha$, the Hessian matrix

$$
\begin{array}{r}
\left|\mathrm{HM}_{m}\right|=\alpha-\frac{e^{2}}{4}>0, \\
\pi_{m}^{m *}\left(w_{m}^{*}, r_{m}^{*}\right) .
\end{array}
$$

has optimal solution. By solving

$$
\begin{aligned}
& \frac{\partial \pi_{m}^{m *}\left(w_{m}^{*}, r_{m}^{*}\right)}{\partial w_{m}^{*}}=0, \\
& \frac{\partial \pi_{m}^{m *}\left(w_{m}^{*}, r_{m}^{*}\right)}{\partial r_{m}^{*}}=0,
\end{aligned}
$$

simultaneously, we can get $w_{m}^{*}$ and $r_{m}^{*}$. Putting $w_{m}^{*}$ and $r_{m}^{*}$ into $p_{m}^{*}\left(w_{m}^{*}, r_{m}^{*}\right)$, we can get $p_{m}^{*}$. From $p_{m}^{*}=w_{m}^{*}+m_{m}^{*}$, we can know $m_{m}^{*}$. This concludes the proof of Proposition 3.
According to known $p_{m}^{*}, w_{m}^{*}, r_{m}^{*}$, we can get the optimal quantity $\left(q_{m}^{*}\right)$ and profit $\pi_{m}^{r *}\left(p_{m}^{*}, w_{m}^{*}, r_{m}^{*}\right)$ and $\pi_{m}^{m *}\left(p_{m}^{*}, w_{m}^{*}, r_{m}^{*}\right)$ of the manufacturer-leading supply chain.

\section{Cost Disturbance Models under Carbon Price Fluctuations}

In Section 4, we assume that the carbon trading market is completely efficient, that the carbon price is fixed at an equilibrium position, and that there are no unreasonable fluctuations. However, carbon price fluctuations in the real economy are bound to exist. Therefore, this part assumes that the carbon trading market is either not strongly efficient (small reasonable fluctuations) or not efficient (large and unreasonable fluctuations). At this time, market information cannot be immediately and completely reflected in the carbon price. The carbon price fluctuates and deviates from equilibrium.

The manufacturer makes carbon emission reduction investment in advance according to the optimal production decision plan $r^{*}$ in the baseline model without carbon price fluctuations. When the cost disturbance caused by the carbon price fluctuations occurs, the supply chain, which has already made the carbon emission reduction investment and cannot change the investment level, can only adjust the product price to cope with cost disturbance. The adjustment of product price will cause the deviation of market demand. When the carbon price fluctuates $o<0$, the unit production cost will decrease, and the optimal price can be lower than the original planned price. At this time, shortage cost $\mu_{1}$ occurs. When the carbon price fluctuates $o<0$, the unit production cost increases, and the optimal price needs to be higher than the original planned price. The market demand is less than the original planned production quantity, resulting in inventory cost $\mu_{2}$. Since deviation costs (shortage cost and inventory cost) are caused by the manufacturer's carbon footprints, the deviation cost will be reflected in the manufacturer's profit function. In the following, we will discuss the operation changes of the supply chain under three different power structures.

5.1. Cost Disturbance Model: Centralized Supply Chain. The target profit function of the centralized supply chain model under carbon price fluctuations can be rewritten as

$$
\tilde{\pi}_{c}(\tilde{p}, \tilde{r})= \begin{cases}\left(\tilde{p}_{c}-c\right) \tilde{q}_{c}-\left(\tilde{q}_{c}-r_{c}^{*}-R\right)(t+o)-\mu_{1}\left(\tilde{q}_{c}-q^{*}\right)-\frac{\alpha r_{c}^{* 2}}{2}, & o<0, \\ \left(\tilde{p}_{c}-c\right) \tilde{q}_{c}-\left(\tilde{q}_{c}-r_{c}^{*}-R\right)(t+o)-\mu_{2}\left(q^{*}-\tilde{q}_{c}\right)-\frac{\alpha r_{c}^{* 2}}{2}, & o>0 .\end{cases}
$$


Using the optimization theory to discuss this profit function, respectively, we can obtain the optimal production decision of centralized supply chain under carbon price fluctuations (the proof is similar to that of Proposition 1, so it will be omitted here).
Proposition 4. The production model has the following optimal decisions under carbon price fluctuations:

$$
\tilde{p}_{c}= \begin{cases}p_{c}^{*}+\frac{1}{2}\left(o+\mu_{1}\right), & o<-\mu_{1}, \\ p_{c}^{*}, & -\mu_{1} \leq o \leq \mu_{2}, \\ p_{c}^{*}+\frac{1}{2}\left(o-\mu_{2}\right), & o>\mu_{2} .\end{cases}
$$

At this time, the optimal quantity of this model is

$$
\tilde{q}_{c}= \begin{cases}q_{c}^{*}-\frac{1}{2}\left(o+\mu_{1}\right), & o<-\mu_{1}, \\ q_{c}^{*}, & -\mu_{1} \leq o \leq \mu_{2}, \\ q_{c}^{*}-\frac{1}{2}\left(o-\mu_{2}\right), & o>\mu_{2} .\end{cases}
$$

Among them, we can find that both $\tilde{p}_{c}$ and $\tilde{q}_{c}$ have three stages by two critical points. The first critical point is $o=-\mu_{1}$, which is due to the fact that when $o<0, \tilde{q}_{c}-q^{*}>0$; and the second critical point is $o=\mu_{2}$, which is due to the fact that when $o>0, q^{*}-\tilde{q}_{c}>0$. By plugging relevant parameters into $\tilde{q}_{c}$ and $q^{*}$, we can get the threshold $o<-\mu_{1}$ if $\tilde{q}_{c}-q^{*}>0$ and $o>\mu_{2}$ if $q^{*}-\tilde{q}_{c}>0$. In addition, when $o$ is in the range of $-\mu_{1} \leq o$ or $o \leq \mu_{2}$, there are no adjusted optimal operations. Thus, in the range of $-\mu_{1} \leq o \leq \mu_{2}$, the supply chain can still maintain the original production plan under the cost disturbance caused by the carbon price fluctuations.

5.2. Cost Disturbance Model: Retailer-Leading Decentralized Supply Chain. The target profit function of the retailerleading decentralized supply chain model under carbon price fluctuations can be rewritten as

$$
\begin{aligned}
& \tilde{\pi}_{r}^{r}\left(\widetilde{w_{r}}, \widetilde{m_{r}}\right)=\widetilde{m_{r} q_{r}}, \\
& \widetilde{\pi_{r}^{m}}\left(\widetilde{w_{r}}, \widetilde{m_{r}}\right)= \begin{cases}\left(\widetilde{w_{r}}-c\right) \tilde{q_{r}}-\left(\tilde{q}_{r}-r_{r}^{*}-R\right)(t+o)-\mu_{1}\left(\tilde{q}_{r}-q_{r}^{*}\right)-\frac{\alpha r_{r}^{* 2}}{2}, & o<0, \\
\left(\widetilde{w_{r}}-c\right) \tilde{q}_{r}-\left(\tilde{q}_{r}-r_{r}^{*}-R\right)(t+o)-\mu_{2}\left(q_{r}^{*}-\tilde{q}_{r}\right)-\frac{\alpha r_{r}^{* 2}}{2}, & o>0 .\end{cases}
\end{aligned}
$$


Using the optimization theory to discuss this profit function, respectively, we can obtain the optimal production decision of retailer-leading decentralized supply chain under carbon price fluctuations (the proof is similar to that of Proposition 2, so it will be omitted here).
Proposition 5. The retailer-leading supply chain model has the following optimal decisions under carbon price fluctuations:

$$
\begin{gathered}
\widetilde{w_{r}}= \begin{cases}\frac{1}{4}\left(3 c+3 o+e r_{r}^{*}+3 t+V+3 \mu_{1}\right), & o<-\mu_{1}+\varepsilon \\
w_{r}^{*}, & -\mu_{1}+\varepsilon \leq o \leq \mu_{2}+\varepsilon, \\
\frac{1}{4}\left(3 c+3 o+e r_{r}^{*}+3 t+V-3 \mu_{2}\right), & o>\mu_{2}+\varepsilon,\end{cases} \\
\widetilde{m_{r}}= \begin{cases}\frac{1}{2}\left(-c-o+e r_{r}^{*}-t+V-\mu_{1}\right), & o<-\mu_{1}+\varepsilon, \\
m_{r}^{*}, & -\mu_{1}+\varepsilon \leq o \leq \mu_{2}+\varepsilon, \\
\frac{1}{2}\left(-c-o+e r_{r}^{*}-t+V+\mu_{2}\right), & o>\mu_{2}+\varepsilon .\end{cases}
\end{gathered}
$$

At this time, the optimal quantity of this model is

$$
\tilde{q}_{r}= \begin{cases}\frac{1}{4}\left(-c-o+e r_{r}^{*}-t+V-\mu_{1}\right), & o<-\mu_{1}+\varepsilon, \\ q_{r}^{*}, & -\mu_{1}+\varepsilon \leq o \leq \mu_{2}+\varepsilon, \\ \frac{1}{4}\left(-c-o+e r_{r}^{*}-t+V+\mu_{2}\right), & o>\mu_{2}+\varepsilon .\end{cases}
$$

Among them, $\varepsilon=e^{2}[e t-(c+t-V) \alpha] / 2\left(e^{2}-2 \alpha\right) \alpha$. According to the assumption above, $\varepsilon<0$.

Like Proposition 4, the optimal production decision can also be divided into the three stages by two critical points, that is, $o=-\mu_{1}+\varepsilon$ and $o=\mu_{2}+\varepsilon$. In the range of $-\mu_{1}+\varepsilon \leq o \leq \mu_{2}+\varepsilon$, the supply chain can still maintain the original production plan under the cost disturbance caused by the carbon price fluctuations.
5.3. Cost Disturbance Model: Manufacturer-Leading Decentralized Supply Chain. The target profit function of the manufacturer-leading decentralized supply chain model under carbon price fluctuations can be rewritten as

$$
\begin{aligned}
& \widetilde{\pi_{m}^{r}}\left(\widetilde{w_{m}}, \widetilde{m_{m}}\right)=\left(\widetilde{p_{m}}-\widetilde{w_{m}}\right) \widetilde{q_{m}}, \\
& \widetilde{\pi_{m}^{m}}\left(\widetilde{w_{m}}, \widetilde{m_{m}}\right)=\left\{\begin{array}{l}
\left(\widetilde{w_{m}}-c\right) \widetilde{q_{m}}-\left(\widetilde{q_{m}}-r_{m}^{*}-R\right)(t+o)-\mu_{1}\left(\widetilde{q_{m}}-q_{m}^{*}\right)-\frac{\alpha r_{m}^{* 2}}{2}, \quad o<0, \\
\left(\widetilde{w_{m}}-c\right) \widetilde{q_{m}}-\left(\widetilde{q_{m}}-r_{m}^{*}-R\right)(t+o)-\mu_{2}\left(q_{m}^{*}-\widetilde{q_{m}}\right)-\frac{\alpha r_{m}^{* 2}}{2}, \quad o>0 .
\end{array}\right.
\end{aligned}
$$


Using the optimization theory to discuss this profit function, respectively, we can obtain the optimal production decision of manufacturer-leading decentralized supply chain under carbon price fluctuations (the proof is similar to that of Proposition 3, so it will be omitted here).

Proposition 6. The manufacturer-leading supply chain model has the following optimal decisions under carbon price fluctuations:

$$
\begin{gathered}
\widetilde{w_{m}}= \begin{cases}\frac{1}{2}\left(c+o+e r_{m}^{*}+t+V+\mu_{1}\right), & o<-\mu_{1}, \\
w_{m}^{*}, & -\mu_{1} \leq o \leq \mu_{2}, \\
\frac{1}{2}\left(c+o+e r_{m}^{*}+t+V-\mu_{2}\right), & o>\mu_{2},\end{cases} \\
\widetilde{m_{m}}= \begin{cases}\frac{1}{4}\left(-c-o+e r_{m}^{*}-t+V-\mu_{1}\right), & o<-\mu_{1}, \\
m_{m}^{*}, & -\mu_{1} \leq o \leq \mu_{2}, \\
\frac{1}{4}\left(-c-o+e r_{m}^{*}-t+V+\mu_{2}\right), & o>\mu_{2} .\end{cases}
\end{gathered}
$$

At this time, the optimal quantity of this model is

$$
\widetilde{q_{m}}= \begin{cases}\frac{1}{4}\left(-c-o+e r-t+V-\mu_{1}\right), & o<-\mu_{1}, \\ m_{m}^{*}, & -\mu_{1} \leq o \leq \mu_{2}, \\ \frac{1}{4}\left(-c-o+e r-t+V+\mu_{2}\right), & o>\mu_{2} .\end{cases}
$$

Like Proposition 4, the optimal production decision can be divided into three stages by two critical points, that is, $o=-\mu_{1}$ and $o=\mu_{2}$. In the range of $-\mu_{1} \leq o \leq \mu_{2}$, the supply chain can still maintain the original production plan under the cost disturbance caused by the carbon price fluctuations.

The overall consideration of Propositions 4-6 can reach the following conclusions about the impacts of carbon price fluctuations on the supply chains.

Corollary 1. The carbon price fluctuations bring cost crisis to supply chains under three different power structures. When the fluctuations are within a certain range (which will be discussed as "robust range" in the below), supply chains can keep the original production plan. In other cases, supply chains have to use the price adjustment to deal with the cost disturbance caused by carbon price fluctuations. It means that the cost disturbance resulting from carbon price fluctuations affects the profit of supply chains and if supply chains refuse to adjust, the optimal profit cannot be reached.

\section{Numerical Examples and Analysis}

In order to better understand the changes in supply chains' operations under carbon price fluctuations, this section will do the numerical examples and analysis. Assume some parameters in that system. $c=3, t=2, e=0.5, V=10, \alpha=$ $8, R=0.5, \mu_{1}=0.25, \mu_{2}=0.5$. In the real economy, the carbon price fluctuations are unlikely to exceed two or three times themselves in a production cycle. Therefore, the following cases only consider the fluctuation range within oc $[-5,5]$.

6.1. Centralized Supply Chain. From Proposition 4, we can see that the carbon price fluctuation $o$ has three stages by two critical points $(o=-0.25$ and $o=0.5)$. We calculate different operations and profitability of the original production plans and the pricing adjustment production plans under carbon price fluctuations. The specific results are shown in Table 2.

The relationship between product price (retail price), production quantity, profit, and carbon price fluctuation can be seen in Figure 2.

Figures 2(a) and 2(b) indicate that when the fluctuation range of carbon price is within the range of $-0.25<0<0.5$ (the region is considered as the robust range), the centralized supply chain does not need to adjust its original production plan. When the carbon price fluctuations are over this range, the product price must be adjusted appropriately to attain better profitability. The purple line in Figure 2(c) indicates that when there is no pricing adjustment, negative carbon price fluctuations bring excess profit to the supply chain, while positive carbon price fluctuations bring excess loss to the supply chain. Comparing the profit of no pricing adjustment (purple line) with pricing adjustment (blue line), we can find that the profit without pricing adjustment is lower than that with pricing adjustment.

6.2. Retailer-Leading Decentralized Supply Chain. In the retailer-leading decentralized supply chain, the carbon price fluctuation $o$ has three stages by two critical points $(o=-0.2906$ and $o=0.4593)$. We calculate different operations and profitability of the original production plans and the pricing adjustment production plans under carbon price fluctuations. Table 3 presents the specific results.

The relationship between product prices (wholesale price and marginal profit), production quantity, profit, and carbon price fluctuation can be seen in Figure 3.

From Figure 3, we can know that the robust range of the retailer-leading supply chain is $-0.2906<0<0.4593$; in this range, the supply chain does not need pricing adjustment. When the carbon price fluctuations are over this range, the product price must be adjusted to deal with the cost disturbance. Figures 3(d)-3(f) present the profit of the retailerleading supply chain with pricing adjustment and without pricing adjustment. When the carbon price fluctuations are outside the robust range, pricing adjustment causes the two members' individual profit to change in the opposite 
TABLE 2: Numerical results of centralized supply chain.

\begin{tabular}{lccccccc}
\hline$o$ & 0 & -0.25 & -0.5 & -1 & 0.5 & 1 \\
\hline$r_{c}^{*}$ & 0.4127 & 0.4127 & 0.4127 & 0.4127 & 0.4127 & 0.4127 & 0.4127 \\
$p_{c}$ & 7.6032 & 7.6032 & 7.4782 & 7.2282 & 7.6032 & 7.8532 \\
$q_{c}$ & 2.6032 & 2.6032 & 2.7282 & 2.9782 & 2.6032 & 2.3532 \\
$\pi_{c}^{*}$ & 7.9206 & 8.3432 & 8.7659 & 9.6111 & 7.0754 & 6.2301 & 2.1032 \\
$\tilde{\pi}_{c}$ & - & 8.3433 & 8.7815 & 9.7517 & 7.0754 & 5.3849 \\
$\Delta \pi_{c}$ & - & 0 & 0.0156 & 0.1407 & 0 & 5.2927 & 0.0625 \\
\hline
\end{tabular}

Note. $\Delta \pi=\tilde{\pi}-\pi^{*}$ and the results are kept to four decimal places.

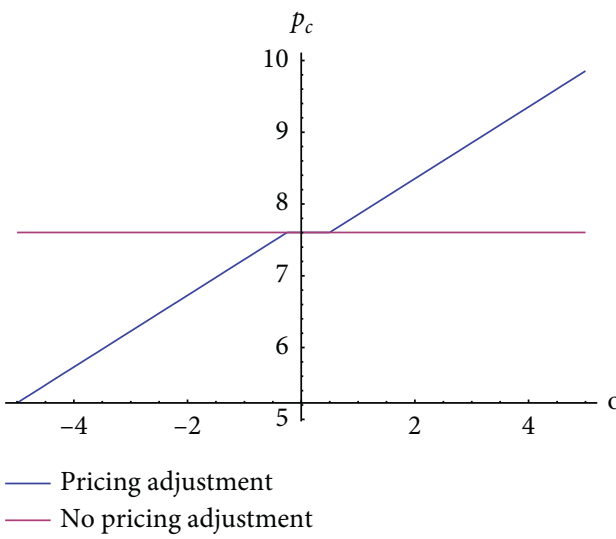

(a)

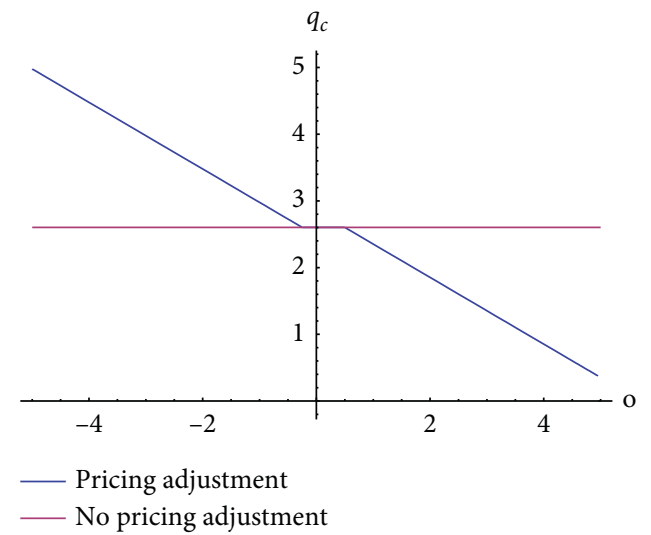

(b)

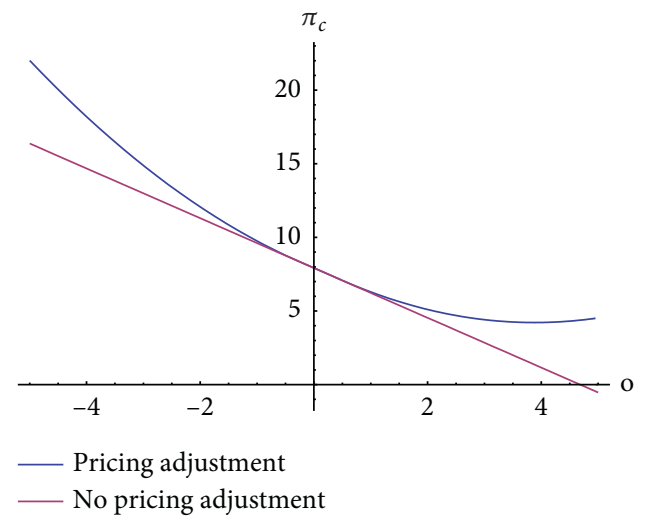

(c)

Figure 2: Numerical results of centralized supply chain. (a) Retail price vs. fluctuations. (b) Production quantity vs. fluctuations. (c) The supply chain profit vs. fluctuations.

TABLE 3: Numerical results of retailer-leading decentralized supply chain.

\begin{tabular}{lccccccc}
\hline$o$ & 0 & -0.2906 & -0.5 & -1 & 0.4593 & 1 \\
\hline$r_{r}^{*}$ & 0.3313 & 0.3313 & 0.3313 & 0.3313 & 0.3313 & 0.3313 \\
$\frac{w_{r}}{m_{r}}$ & 6.3016 & 6.2610 & 6.1039 & 5.7289 & 6.2609 & 6.6664 \\
$\widetilde{p}_{r}$ & 2.5625 & 2.6031 & 2.7078 & 2.9578 & 2.6032 & 2.3328 \\
$\widetilde{q}_{r}$ & 8.8641 & 8.8641 & 8.8118 & 8.6868 & 8.8641 & 8.9993 \\
$\pi_{r}^{r *}$ & 1.3016 & 1.3016 & 1.3539 & 1.4789 & 1.3016 & 1.1664 \\
$\tilde{\pi}_{r}^{r}$ & 3.3353 & 3.3353 & 3.3353 & 3.3353 & 3.3353 & 3.3353 \\
$\Delta \pi_{r}^{r}$ & - & 3.3882 & 3.6662 & 4.3744 & 3.3883 & 2.0828 \\
$\pi_{r}^{m}{ }^{m}$ & - & 0.0528 & 0.3309 & 1.0391 & 0.0530 & -0.6143 \\
$\pi_{r}^{m}$ & 2.9177 & 3.0543 & 3.1528 & 3.3879 & 2.7017 & 3.3353 \\
$\Delta \pi_{r}^{m}$ & - & 3.0014 & 2.9664 & 2.9048 & 2.6487 & 2.1691 \\
\hline
\end{tabular}




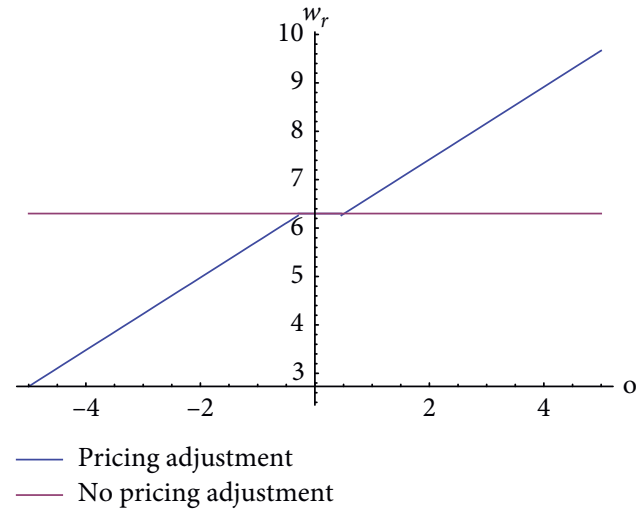

(a)

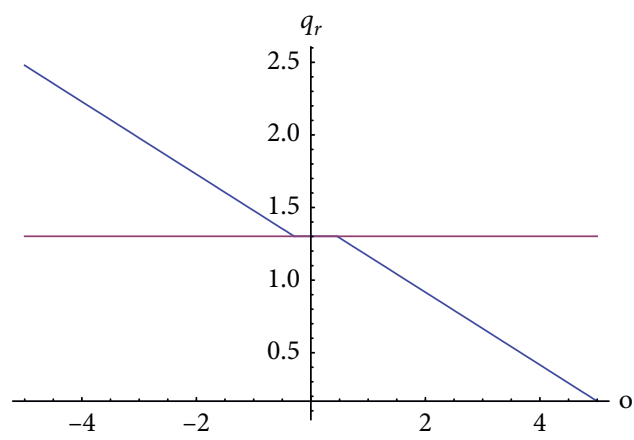

- Pricing adjustment

__ No pricing adjustment

(c)

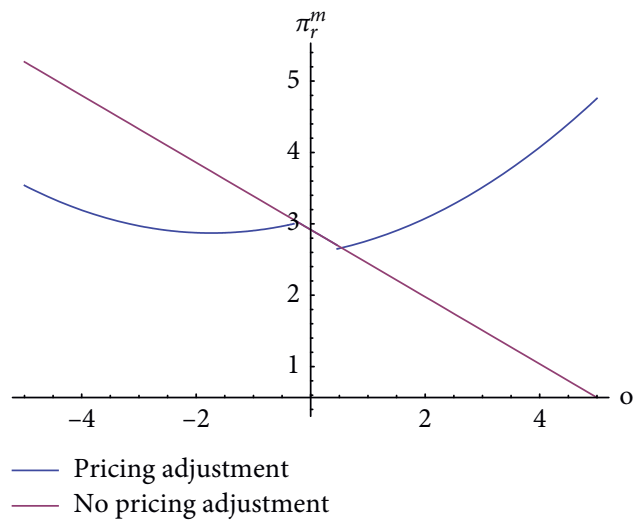

(e)

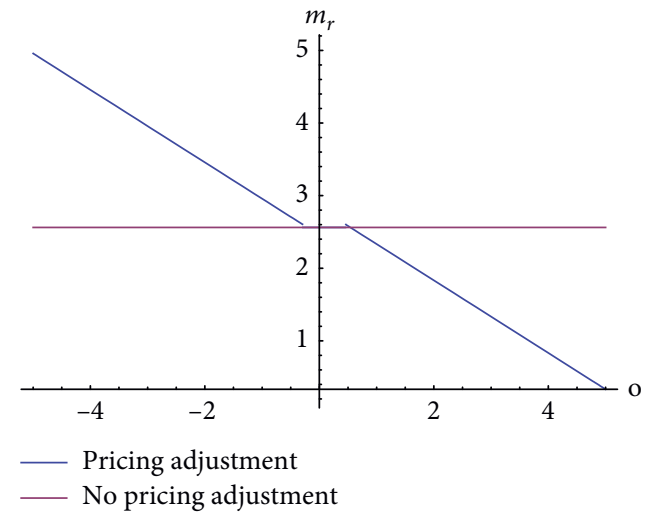

(b)

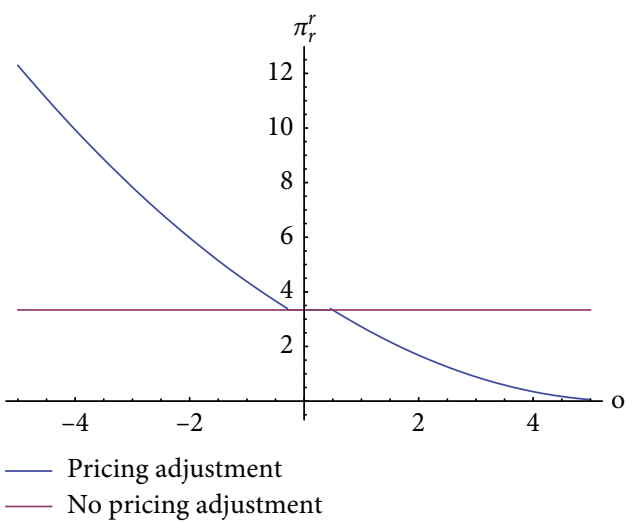

(d)

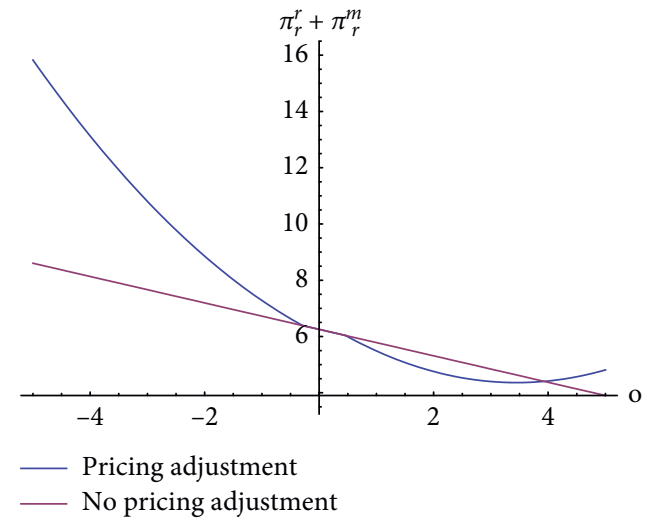

(f)

FIGURE 3: Numerical results of retailer-leading decentralized supply chain. (a) Wholesale price vs. fluctuations. (b) Marginal profit vs. fluctuations. (c) Production quantity vs. fluctuations. (d) The manufacturer profit vs. fluctuations. (e) The retailer profit vs. fluctuations. (f) The whole supply chain profit vs. fluctuations.

directions. For the retailer, when the carbon price fluctuations are in the range of $o>0.4593$, the profit after price adjustment is lower than the unadjusted profit. The retailer as the leader of the supply chain has no motivation to make pricing adjustments in this range. Therefore, it is impossible for the manufacturer to obtain increased profit after pricing adjustment. Because the retailer rejects the pricing adjustment in the range of $o>0.4593$, when $o<-0.2906$, we can know from the profit of the whole supply chain that the carbon price fluctuations will bring cost disturbance to the supply chain. Furthermore, pricing adjustment rather than no pricing adjustment can bring higher profit to the supply chain.

6.3. Manufacturer-Leading Decentralized Supply Chain. In the manufacturer-leading decentralized supply chain, the carbon price fluctuation $o$ also has three stages by two critical points $(o=-0.25$ and $o=0.5)$. We calculate the production plans and profitability of the original production plans and 
the pricing adjustment production plans under carbon price fluctuations. Table 4 shows the numerical results of manufacturer-leading decentralized supply chain.

The relationship between product prices (wholesale price and marginal profit), production quantity, profit, and carbon price fluctuation can be seen in Figure 4 .

From Figure 4, we can know that the manufacturerleading supply chain has the same robust range $(-0.25<o<0.5)$ as the centralized supply chain. When the carbon price fluctuations are over the range of $-0.25<o<0.5$, the product price must be adjusted to cope with the risk of cost disturbance. Figures $4(\mathrm{~d})-4(\mathrm{f})$ present the profit of the manufacturer-leading supply chain with and without pricing adjustment. When the carbon price fluctuations are in the range of $o>0.5$, the profit of retailer after pricing adjustment is lower than the profit without adjustment. However, in the manufacturer-leading supply chain, retailer can only passively accept the pricing adjustment or withdraw the supply chain. For the manufacturer, whether the carbon price fluctuations are in the range of $o<-0.25$ or $o>0.5$, pricing adjustment will bring higher profit to it in both cases. When the carbon price fluctuations are in the range of $o<-0.25$, the profit of the whole supply chain increases after pricing adjustment. When the carbon price fluctuations are in the range of $o>0.5$, the profit of the whole supply chain after pricing adjustment is inverted in a $\mathrm{U}$ shape, which is caused by the decrease of retailer's profit.

6.4. Comparative Study of Supply Chains with Three Different Power Structures under Carbon Price Fluctuations. In Sections 6.1-6.3, we make a comparison of the changes in optimal production decision under the same power structure with and without carbon price fluctuations (whether the carbon trading market is completely efficient or not). This section will examine the operation changes in supply chains under different power structures with carbon price fluctuations. This section is mainly divided into three parts: comparison of the robust range, comparison of profitability with and without carbon price fluctuations, and the ranking of carbon emission reduction levels.

6.4.1. The Robust Range. According to the models of Sections 5.1-5.3, we can draw conclusions about the robust range of the supply chain under different power structures. Here we define robustness as the characteristic where supply chains can keep the original production plan unchanged under the cost disturbance, which can be represented by the length of the robust range. In other words, robustness reflects the ability of supply chains to resist the cost disturbance.

Corollary 2. Under the cost disturbance caused by carbon price fluctuations, the robust ranges of the centralized supply chain and manufacturer-leading decentralized supply chain are $-\mu_{1} \leq o \leq \mu_{2}$, and that of the retailer-leading decentralized supply chain is $-\mu_{1}+\varepsilon \leq o \leq \mu_{2}+\varepsilon$. The lengths of the robust ranges under three power structures are the same (i.e., $\left.\mu_{1}+\mu_{2}\right)$. The robust range of the retailer-leading decentralized
TABLE 4: Numerical results of manufacturer-leading decentralized supply chain.

\begin{tabular}{lccccccc}
\hline$o$ & 0 & -0.25 & -0.5 & -1 & 0.5 & 1 & 1.5 \\
\hline$r_{m}^{*}$ & 0.3307 & 0.3307 & 0.3307 & 0.3307 & 0.3307 & 0.3307 & 0.3307 \\
$\frac{w_{m}}{m_{m}}$ & 7.5827 & 7.5827 & 7.4577 & 7.2077 & 7.5827 & 7.8327 & 8.0827 \\
$\widetilde{p_{m}}$ & 8.8740 & 1.2913 & 1.3538 & 1.4788 & 1.2913 & 1.1663 & 1.0413 \\
${\widetilde{q_{m}}}^{r *}$ & 1.2913 & 1.2913 & 1.3538 & 1.4788 & 1.2913 & 1.1663 & 1.0413 \\
$\pi_{m}^{r *}$ & 1.6676 & 1.6676 & 1.6676 & 1.6676 & 1.6676 & 1.6676 & 1.6676 \\
$\pi_{m}^{r}$ & - & 1.6676 & 1.8329 & 2.1870 & 1.6676 & 1.3604 & 1.0844 \\
$\Delta \pi_{m}^{r}$ & - & 0 & 0.1653 & 0.5194 & 0 & -0.3072 & -0.5832 \\
$\pi_{m}^{m *}$ & 4.5591 & 4.6742 & 4.7894 & 5.0197 & 4.3287 & 4.0984 & 3.8681 \\
$\pi_{m}^{m}$ & - & 4.6742 & 4.7972 & 5.0900 & 4.3287 & 4.1297 & 3.9931 \\
$\Delta \pi_{m}^{m}$ & - & 0 & 0.0078 & 0.0703 & 0 & 0.0312 & 0.1250 \\
\hline
\end{tabular}

supply chain shifts $\varepsilon$ units to the left compared to the other power structure cases.

The managerial insights of this result can be explained as follows: in all kinds of power structures of the supply chain, the determining factor of the length of the robust ranges is the deviation cost, which comes from the shortage and inventory problems. The higher the cost of shortage and inventory issues, the more robust the supply chain. On the contrary, the lower the cost of the supply chain coping with shortage and inventory issues, the shorter the robust range. At the same time, we find that the robust range of the retailer-leading decentralized supply chain has left trend compared to the other two power structure cases of the supply chain, so it has higher ability to resist the risk when the carbon price fluctuations are mostly negative. That is, if the carbon prices in the carbon trading market are frequently below the equilibrium price, the use of retailer-leading decentralized supply chain can avoid frequent operation adjustments.

6.4.2. The Profitability. In order to visually compare the profit changes of the retailers, manufacturers, and whole supply chains under different power structure cases with carbon price fluctuations, we draw Figure 5, which shows the relationship between the profit and carbon price fluctuations of retailers, manufacturers, and whole supply chains.

According to Figure 5, we can get the observations on profit of the retailer, manufacturer, and whole supply chain under three different power structure cases with and without carbon price fluctuations.

Observation 1. In the retailer-leading decentralized supply chain with carbon price fluctuations, the retailer's profit is significantly higher than the manufacturer's profit; in the manufacturer-leading decentralized supply chain with carbon price fluctuations, the manufacturer's profit is significantly higher than the retailer's profit.

Observation 2. Two decentralized power structure cases of the supply chain have a similar whole supply chain profit, while the centralized supply chain has significantly higher whole supply chain profit than the two decentralized power structure cases. 


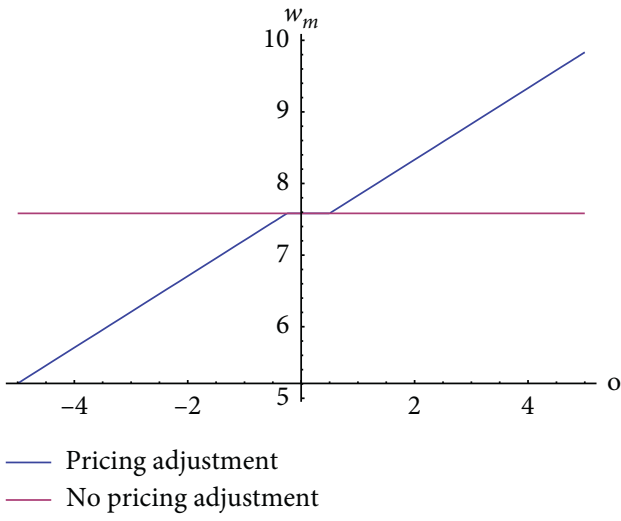

(a)

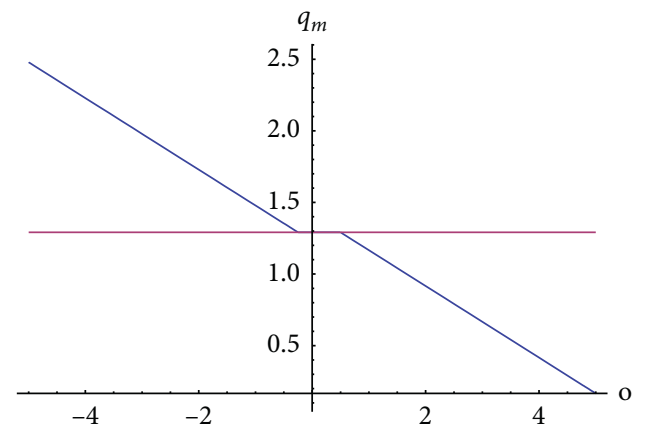

_ Pricing adjustment

_ No pricing adjustment

(c)

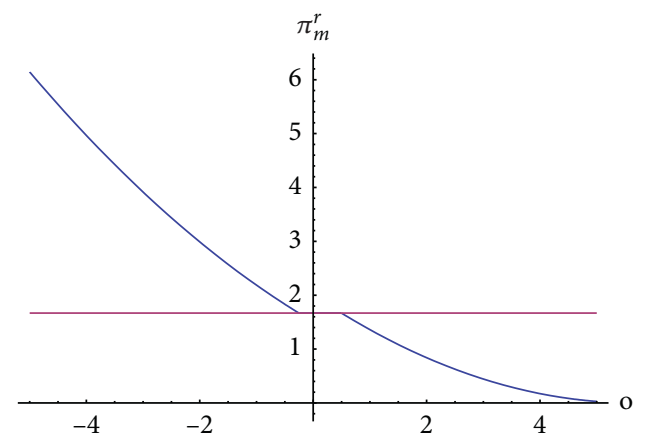

— Pricing adjustment

_ No pricing adjustment

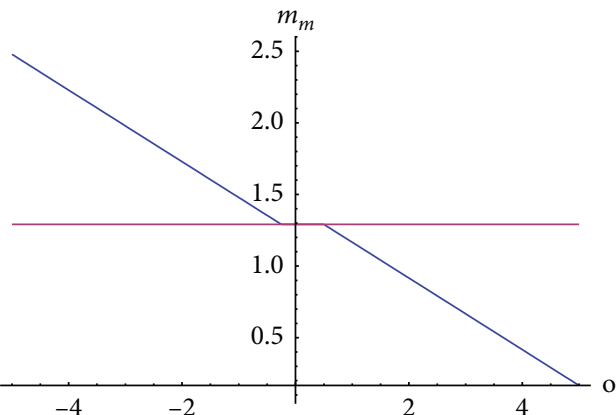

_ Pricing adjustment

_ No pricing adjustment

(b)

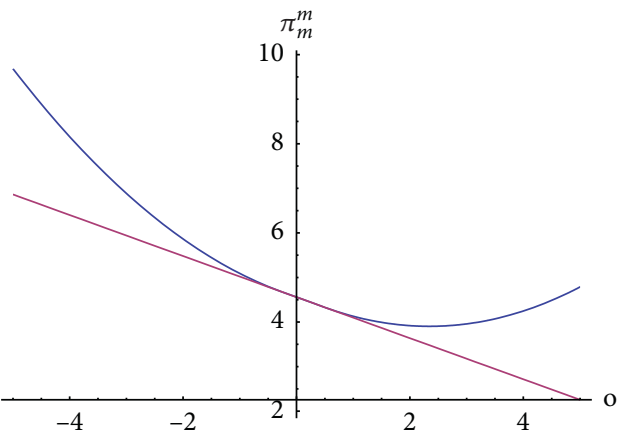

— Pricing adjustment

_ No pricing adjustment

(d)

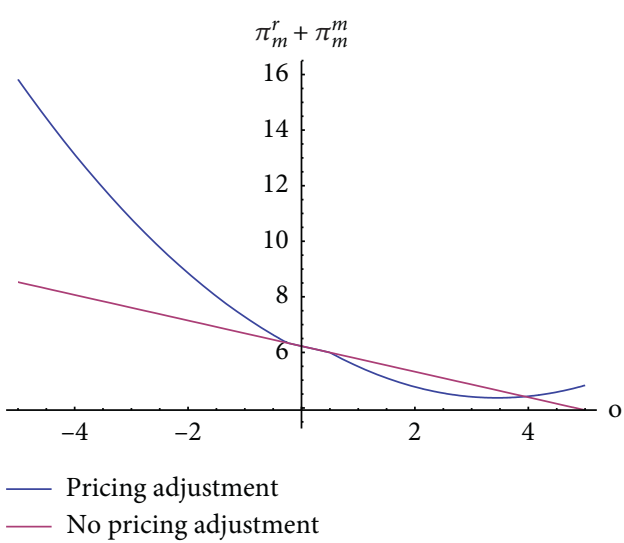

(f)

Figure 4: Numerical results of manufacturer-leading decentralized supply chain. (a) Wholesale price vs. fluctuations. (b) Marginal profit vs. fluctuations. (c) Production quantity vs. fluctuations. (d) The manufacturer profit vs. fluctuations. (e) The retailer profit vs. fluctuations. (f) The whole supply chain profit vs. fluctuations.

Observation 1 can be interpreted as follows: the retailer or manufacturer with stronger bargaining power in the supply chain will gain advantage in profit distribution, which is why the retailer's profit is higher in the retailer-leading power structure case, while the manufacturer has higher profit in the manufacturer-leading power structure case. That phenomenon is in line with real economy. It can be seen from Observation 2 that the profits of the two decentralized cases are similar and significantly lower than that of the centralized case. The reason for this result can be explained as follows: in the centralized supply chain, the retailer and the manufacturer making the production decisions concertedly can reduce the efficiency loss caused by the game between the retailer and the manufacturer. In other 


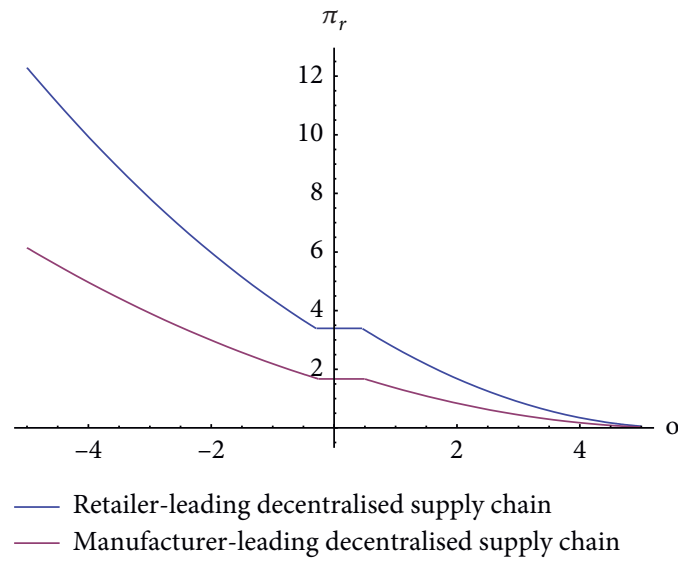

(a)

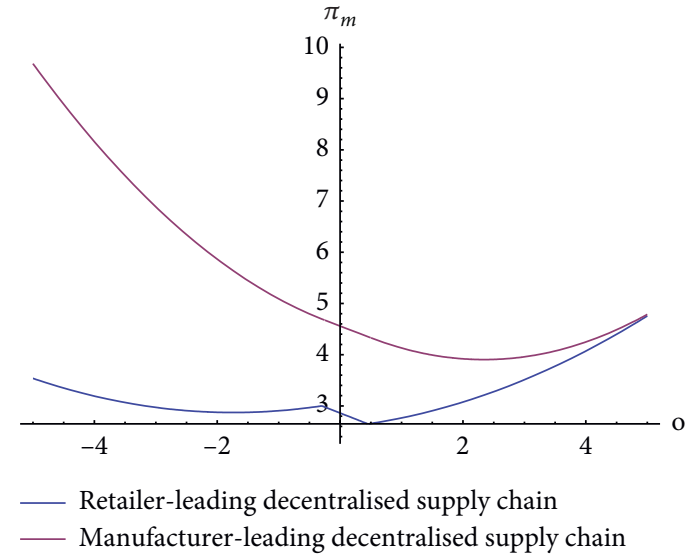

(b)

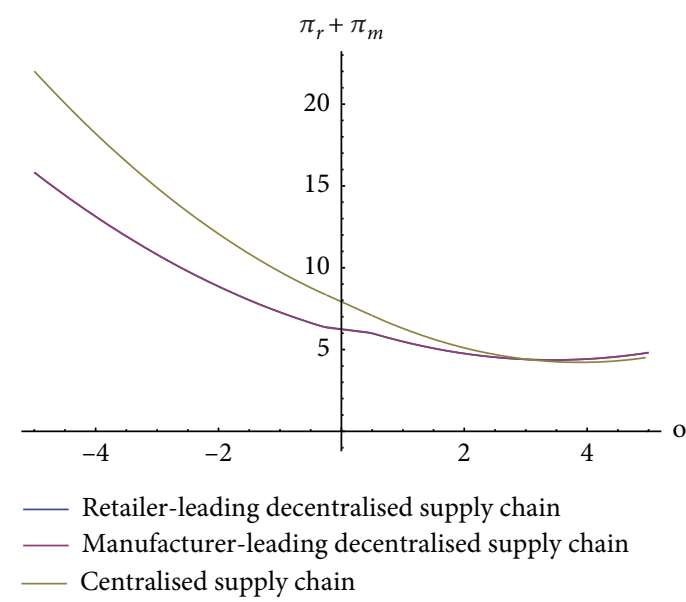

(c)

Figure 5: The profit under different power structures. (a) The profit of the retailers vs. fluctuations. (b) The profit of the manufacturers vs. fluctuations. (c) The profit of the whole supply chains vs. fluctuations.

words, centralized supply chain has higher profit and production efficiency than the other two decentralized cases with and without the carbon price fluctuations.

6.4.3. The Ranking of Carbon Emission Reduction Levels. The carbon emission reduction investments were made according to the optimal production decision of the baseline model at the beginning of the period. Therefore, the coefficient $r$ of carbon emission reduction investment intuitively reflects the carbon emission reduction investment level. Furthermore, in order to further understand the carbon emission reduction levels of three different power structure cases in the supply chain, here we consider the indicator of actual carbon emission output per unit: $E=(q-r-R / q)$. The numerical results of the carbon emission reduction investment levels are shown in Table 5.

In order to directly compare the changes of actual carbon emission output per unit under the carbon price fluctuations in the supply chain under different power structures, we present Figure 6.

Based on the above discussion, we can draw observations on the ranking of carbon emission reduction investment levels of the supply chain under different power structures with carbon price fluctuations.

Observation 3. From the perspective of carbon emission reduction investment coefficient $r$, centralized supply chain $>$ retailer-leading decentralized supply chain $>$ manufacturer-leading decentralized supply chain. In the two decentralized power structure cases, the carbon emission reduction investment levels are similar, while the carbon emission reduction investment level of the centralized supply chain is significantly higher than the two decentralized power structure cases.

Observation 4. From the perspective of actual carbon emission output per unit $\mathrm{E}$, the actual carbon emission output per unit of the centralized supply chain is much higher than that of the two decentralized cases in the supply chain.

From the above observations, under the optimal conditions, the carbon emission reduction investment level of the centralized case is higher than that of the other two decentralized cases in the supply chain, but the centralized 
TABLE 5: Numerical results of carbon emission reduction investment levels.

\begin{tabular}{|c|c|c|c|c|c|c|}
\hline Power structures & $r$ & $E^{*}$ & $E^{o=-0.5}$ & $E^{o=-1}$ & $E^{o=1}$ & $E^{o=1.5}$ \\
\hline Centralized & 0.4127 & 0.6494 & 0.6655 & 0.6935 & 0.6121 & 0.5660 \\
\hline Retailer-leading decentralized & 0.3313 & 0.3613 & 0.3860 & 0.4379 & 0.2873 & 0.2017 \\
\hline Manufacturer-leading decentralized & 0.3307 & 0.3567 & 0.3864 & 0.4383 & 0.2877 & 0.2022 \\
\hline
\end{tabular}

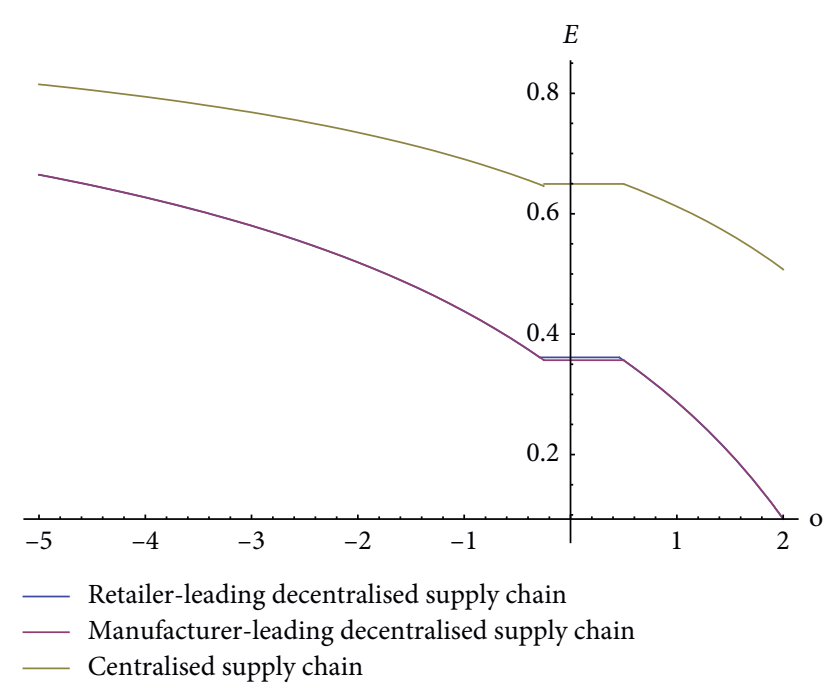

FIgURE 6: Carbon emission output per unit vs. fluctuations.

case's actual carbon emission output per unit (E) is not lower than the two decentralized cases. This contradiction is caused by the different increase rates of carbon emission reduction investment level and production quantity. The production quantity of the centralized case is about twice as much as that of the two decentralized cases in the supply chain, but the carbon emission reduction level in the centralized case is about 1.3 times as much as that of the decentralized cases. That is to say, compared with the decentralized cases, in the centralized supply chain, the optimal production quantity magnification is greater than the carbon emission reduction investment magnification. In other words, although the centralized supply chain avoids the efficiency loss caused by the game between the retailer and manufacturer, it makes less effort on environmental responsibility.

\section{Conclusion}

This paper focuses on the reaction of environmentally responsible supply chains when they are under the cost disturbance caused by carbon price fluctuations in the carbon emission reduction background. This paper also considers three different power structures (centralized, the retailerleading decentralized, and the manufacture-leading decentralized) of the two-echelon supply chain with one retailer and one manufacturer, providing managers with a theoretical basis for coping with carbon price fluctuations in the actual production process. In order to fully understand the impacts of carbon price fluctuations on the supply chain under three different power structures, this paper compares the operations, profitability, and robustness in the same power structure supply chain with and without carbon price fluctuations and compares that under different power structure cases with carbon price fluctuations.

Our study gains the following conclusions. Under three different power structure cases of the two-echelon supply chain, the carbon price fluctuations affect the original optimal decisions and the supply chain has to do pricing adjustment to cope with the cost disturbance caused by the carbon price fluctuations. Moreover, with carbon price fluctuations, three different power structure cases in the supply chain have the same length of the robust range and their robust ranges are mainly determined by the shortage cost and inventory cost caused by the pricing adjustment. The retailer-leading decentralized supply chain's robust range shifts to the left compared to the other two power structures' robust range. Furthermore, with the carbon price fluctuations, the whole supply chain profit of the centralized supply chain is higher than that of the two decentralized cases. The retailer can achieve higher profit in the retailer-leading supply chain, while the manufacturer can achieve higher profit in the manufacturerleading supply chain. The coefficient of the carbon emission reduction investment level in the centralized supply chain is higher than that of the two decentralized cases, but its actual carbon emission output per unit is not lower. Based on the above conclusions, our work improves the understanding of the carbon price fluctuations in supply chains and provides operation reference to managers when facing the cost disturbance caused by carbon price fluctuations.

However, there are some questions that remain to be answered when supply chains face cost disturbance under carbon price fluctuations. Our future research can be extended to the following directions:

(1) This paper only considers that the cost disturbance caused by carbon price fluctuations will affect manufacturers' profit function. The future study could focus on the influence of carbon price fluctuations on retailers or other disturbances.

(2) Unlike the setting of one retailer and one manufacturer in this paper, supply chains in real life would be more complicated. The models in this paper can be modified to multiple retailers and manufacturers. In addition, the relation among manufacturers and retailers can be cooperative, partially cooperative, or competitive.

\section{Data Availability}

The data used to support the findings of this study are available from the corresponding author upon request. 


\section{Conflicts of Interest}

This paper includes the names of some companies. They are well-known examples to illustrate the real-world significance of the study. The authors declare that there are no conflicts of interest regarding the publication of this paper.

\section{Acknowledgments}

This work was supported by the Chinese National Social Science Foundation (no. 18VDL012), Joint PhD candidates Project of China State Scholarship Fund (no. 201906650008) and National Natural Science Foundation of China (no. 71473039).

\section{References}

[1] D. Ni, K. W. Li, and X. Tang, "Social responsibility allocation in two-echelon supply chains: insights from wholesale price contracts," European Journal of Operational Research, vol. 207, no. 3, pp. 1269-1279, 2010.

[2] D. Ni and K. W. Li, "A game-theoretic analysis of social responsibility conduct in two-echelon supply chains," International Journal of Production Economics, vol. 138, no. 2, pp. 303-313, 2012.

[3] C. Wang, W. Wang, and R. Huang, "Supply chain enterprise operations and government carbon tax decisions considering carbon emissions," Journal of Cleaner Production, vol. 152, pp. 271-280, 2017.

[4] S. Zhang, C. Wang, C. Yu, and Y. Ren, "Governmental cap regulation and manufacturer's low carbon strategy in a supply chain with different power structures," Computers \& Industrial Engineering, vol. 134, pp. 27-36, 2019.

[5] B. Zheng, N. Yu, L. Jin, and H. Xia, "Effects of power structure on manufacturer encroachment in a closed-loop supply chain," Computers \& Industrial Engineering, vol. 137, p. 106062, 2019.

[6] Y. Cheng, Z. Xiong, and Q. Luo, "Joint pricing and product carbon footprint decisions and coordination of supply chain with cap-and-trade regulation," Sustainability, vol. 10, no. 2, p. 481, 2018.

[7] J. M. C. Martí, J.-S. Tancrez, and R. W. Seifert, "Carbon footprint and responsiveness trade-offs in supply chain network design," International Journal of Production Economics, vol. 166, pp. 129-142, 2015.

[8] A. Zakeri, F. Dehghanian, B. Fahimnia, and J. Sarkis, "Carbon pricing versus emissions trading: a supply chain planning perspective," International Journal of Production Economics, vol. 164, pp. 197-205, 2015.

[9] J. Bian, X. Guo, and K. W. Li, "Decentralization or integration: distribution channel selection under environmental taxation," Transportation Research Part E: Logistics and Transportation Review, vol. 113, pp. 170-193, 2018.

[10] W. Jiang and X. Chen, "Optimal strategies for low carbon supply chain with strategic customer behavior and green technology investment," Discrete Dynamics in Nature and Society, vol. 2016, Article ID 9645087, 13 pages, 2016.

[11] X. Chen and X. Wang, "Achieve a low carbon supply chain through product mix," Industrial Management \& Data Systems, vol. 117, no. 10, pp. 2468-2484, 2017.

[12] M. Wang, L. Zhao, and M. Herty, "Modelling carbon trading and refrigerated logistics services within a fresh food supply chain under carbon cap-and-trade regulation," International
Journal of Production Research, vol. 56, no. 12, pp. 4207-4225, 2018.

[13] M. Wang, L. Zhao, and M. Herty, "Joint replenishment and carbon trading in fresh food supply chains," European Journal of Operational Research, vol. 277, no. 2, pp. 561-573, 2019.

[14] B. Yuan, B. Gu, J. Guo, L. Xia, and C. Xu, "The optimal decisions for a sustainable supply chain with carbon information asymmetry under cap-and-trade," Sustainability, vol. 10, no. 4, p. 1002, 2018.

[15] L. Xu, C. Wang, and J. Zhao, "Decision and coordination in the dual-channel supply chain considering cap-and-trade regulation," Journal of Cleaner Production, vol. 197, pp. 551561, 2018.

[16] Q. Pang, M. Li, T. Yang, and Y. Shen, "Supply chain coordination with carbon trading price and consumers' environmental awareness dependent demand," Mathematical Problems in Engineering, vol. 2018, Article ID 8749251, 11 pages, 2018.

[17] X. Wang, M. Xue, and L. Xing, "Analysis of carbon emission reduction in a dual-channel supply chain with cap-and-trade regulation and low-carbon preference," Sustainability, vol. 10, no. 3, p. 580, 2018.

[18] J. Xu, Y. Chen, and Q. Bai, “A two-echelon sustainable supply chain coordination under cap-and-trade regulation," Journal of Cleaner Production, vol. 135, pp. 42-56, 2016.

[19] Q. Bai, J. Xu, and Y. Zhang, "Emission reduction decision and coordination of a make-to-order supply chain with two products under cap-and-trade regulation," Computers \& Industrial Engineering, vol. 119, pp. 131-145, 2018.

[20] A. Memari, R. Ahmad, A. Rahim, and M. Jokar, "An optimization study of a palm oil-based regional bio-energy supply chain under carbon pricing and trading policies," Clean Technologies and Environmental Policy, vol. 20, no. 1, pp. 113-125, 2018.

[21] Y. Chen, B. Li, Q. Bai, and Z. Liu, "Decision-making and environmental implications under cap-and-trade and takeback regulations," International Journal of Environmental Research and Public Health, vol. 15, no. 4, p. 678, 2018.

[22] H. Peng, T. Pang, and J. Cong, "Coordination contracts for a supply chain with yield uncertainty and low-carbon preference," Journal of Cleaner Production, vol. 205, pp. 291-302, 2018.

[23] L. Xu, F. Xie, Q. Yuan, and J. Chen, "Pricing and carbon footprint in a two-echelon supply chain under cap-and-trade regulation," International Journal of Low-Carbon Technologies, vol. 14, no. 2, pp. 212-221, 2019.

[24] Z. Chen, C. Teng, D. Zhang, and J. Sun, "Modelling intersupply chain competition with resource limitation and demand disruption," International Journal of Systems Science, vol. 47, no. 7, pp. 1644-1658, 2016.

[25] B. Shen and Q. Li, "Market disruptions in supply chains: a review of operational models," International Transactions in Operational Research, vol. 24, no. 4, pp. 697-711, 2017.

[26] Y. Huang and Z. Wang, "Demand disruptions, pricing and production decisions in a closed-loop supply chain with technology licensing," Journal of Cleaner Production, vol. 191, pp. 248-260, 2018.

[27] K. Rahmani and M. Yavari, "Pricing policies for a dualchannel green supply chain under demand disruptions," Computers \& Industrial Engineering, vol. 127, pp. 493-510, 2019.

[28] N. Wang, X. Fang, Q. Gou, and L. Liang, "Supply chain performance under pull or push contracts in the presence of a 
market disruption," International Transactions in Operational Research, vol. 24, no. 4, pp. 713-736, 2017.

[29] S. M. Ali, M. H. Rahman, T. J. Tumpa, A. A. Moghul Rifat, and S. K. Paul, "Examining price and service competition among retailers in a supply chain under potential demand disruption," Journal of Retailing and Consumer Services, vol. 40, pp. $40-47,2018$.

[30] Y. Zheng, T. Shu, S. Wang, S. Chen, K. Lai, and L. Gan, "Demand disruption and coordination of supply chain via effort and revenue sharing," Applied Economics, vol. 47, no. 54, pp. 5886-5901, 2015.

[31] S. Sardar and Y. H. Lee, "Analysis of product complexity considering disruption cost in fast fashion supply chain," Mathematical Problems in Engineering, vol. 2015, Article ID 670831, 15 pages, 2015.

[32] X. Han, H. Wu, Q. Yang, and J. Shang, "Collection channel and production decisions in a closed-loop supply chain with remanufacturing cost disruption," International Journal of Production Research, vol. 55, no. 4, pp. 1147-1167, 2017.

[33] Y. Huang and Z. Wang, "Dual-recycling channel decision in a closed-loop supply chain with cost disruptions," Sustainability, vol. 9, no. 11, p. 2004, 2017.

[34] H. Wu, X. Han, Q. Yang, and X. Pu, "Production and coordination decisions in a closed-loop supply chain with remanufacturing cost disruptions when retailers compete," Journal of Intelligent Manufacturing, vol. 29, no. 1, pp. 227235, 2018.

[35] P. Zhang, Y. Xiong, and Z. Xiong, "Coordination of a dualchannel supply chain after demand or production cost disruptions," International Journal of Production Research, vol. 53, no. 10, pp. 3141-3160, 2015.

[36] H. Zhang, Y. Liu, and J. Huang, "Supply chain coordination contracts under double sided disruptions simultaneously," Mathematical Problems in Engineering, vol. 2015, Article ID 812043, 9 pages, 2015.

[37] E. Cao, X. Zhou, and K. Lü, "Coordinating a supply chain under demand and cost disruptions," International Journal of Production Research, vol. 53, no. 12, pp. 3735-3752, 2015.

[38] F. Soleimani, A. Khamseh, and B. Naderi, "Optimal decisions in a dual-channel supply chain under simultaneous demand and production cost disruptions," Annals of Operations Research, vol. 243, no. 1-2, pp. 301-321, 2016.

[39] C. Tang, H. Yang, E. Cao, and K. K. Lai, "Channel competition and coordination of a dual-channel supply chain with demand and cost disruptions," Applied Economics, vol. 50, no. 46, pp. 4999-5016, 2018.

[40] J. Ji, Z. Zhang, and L. Yang, "Carbon emission reduction decisions in the retail-/dual-channel supply chain with consumers' preference," Journal of Cleaner Production, vol. 141, pp. 852-867, 2017. 